\title{
El fuero académico en la Real Universidad de México y otras atribuciones de su rector: $1597-1640$
}

\author{
Gustavo Hernández Sánchez ${ }^{1}$
}

Resumen. El presente artículo estudia el fuero académico de la Real Universidad de México entre los años de 1597 y 1640. Éste recaía sobre el rector de la Universidad, el cual además desempeñaba otras atribuciones referentes a disciplina y administración de la vida cotidiana del Estudio. A partir de una perspectiva comparada con el fuero universitario de la Universidad de Salamanca, el cual actuaba como referente en la concesión de este privilegio jurisdiccional para otros Estudios de la Monarquía Hispánica, se llega a la conclusión de que es preferible su investigación desde las características concretas que presentaban tanto la sociedad novohispana de la época como la administración de la justicia en Nuevo México. De este modo, analizamos cómo la puesta en funcionamiento del fuero académico mexicano coincidió con la consolidación de la corporación universitaria de la Real Universidad de México, abriéndose una interesante línea de investigación en este campo.

Palabras clave: fuero académico; corporación universitaria; Real Universidad de México; Universidad de Salamanca.

\section{[en] The Academic Jurisdiction at the Royal University of Mexico and other Attributions of its Rector: 1597-1640}

\begin{abstract}
This paper examines the academic jurisdiction of the Royal University of Mexico between 1597 and 1640. This relayed on the rector of the University, which also had other attributions regarding discipline and administration of the daily life of the University. From a comparison with the University of Salamanca, which acted as a leader in the provision of this jurisdictional privilege, we came to the conclusion that it is preferable to research from the specific characteristics that had both the colonial society as the administration of justice in New Mexico. Thus, we observed that the commissioning of the Mexican academic jurisdiction coincides with the consolidation of the university corporation, opening an interesting line of research in this field.
\end{abstract}

\footnotetext{
Universidad de Salamanca

gustavohistoria@usal.es

Gustavo Hernández Sánchez es investigador predoctoral FPU (ref. AP2012-0881) adscrito al Departamento de Historia Medieval, Moderna y Contemporánea de la Universidad de Salamanca. Miembro del Grupo de Investigación Reconocido (GIR) "Historia cultural y universidades Alfonso IX" de la Universidad de Salamanca; investigador, con dedicación compartida, del proyecto de investigación titulado "Las Universidades Hispánicas (siglos XV-XIX): España, Portugal, Italia y México. Historia, Saberes e Imagen” (ref. HAR2012-30663); y miembro del Instituto de Estudios Medievales y Renacentistas (IEMYR) de la Universidad de Salamanca. El presente trabajo se realizó en el marco de la Beca Teixidor para realizar una estancia de investigación en la Ciudad de México del Instituto de Investigaciones Históricas de la UNAM (convocatoria 2014). Agradezco, del mismo modo, el apoyo recibido por parte del Instituto de Investigaciones sobre la Universidad y la Educación (IISUE) de la UNAM, durante mi estancia de investigación, especialmente de los profesores Armando Pavón Romero y Clara Inés Ramírez González.
} 
Keywords: Academic jurisdiction; University Corporation; Royal University of Mexico; University of Salamanca.

Sumario. 1. Introducción: el fuero académico como signo de autonomía de las corporaciones universitarias en el antiguo régimen. 2. Administración de la Justicia En Ciudad de México: ¿Dónde situar la jurisdicción uni-versitaria de la Real Universidad de México? 3. Características de la ju-risdicción universitaria mexicana: $\tan$ cerca y tan lejos de Salamanca. 4. El ejercicio de la justicia universitaria y otras acciones cotidianas del rector en la Real Universidad de México: la consolidación de la corporación universitaria mexicana. 5. Algunas conclusiones: alcance de la autonomía de la corporación universitaria mexicana.

Cómo citar: Hernández Sánchez, G. (2017) El fuero académico en la Real Universidad de México y otras atribuciones de su rector: 1597-1640, en Cuadernos de Historia Moderna 42.1, 129-149.

A la memoria de los 43 estudiantes desaparecidos en Iguala (México) durante mi estancia en el país. A sus familias. Su dolor es nuestro dolor. Nuestra es también su digna rabia

\section{Introducción: el fuero académico como signo de autonomía de las corporaciones universitarias en el antiguo régimen}

El fuero privativo o privilegio jurisdiccional es uno de los signos externos más importantes de la autonomía de la que gozaron determinadas corporaciones durante el Antiguo Régimen, la corporación universitaria fue una de ellas. En este trabajo tan sólo nos referiremos al fuero o privilegio de la corporación universitaria, con lo que precisamos definir, en primer lugar, qué entendemos por privilegio o fuero académico o universitario (que en el texto empleamos como sinónimos):

Los privilegios son, en principio, documentos otorgados por una autoridad exterior (normalmente el papa o el rey) para conceder derechos o libertades que perfilan el estatuto personal de maestros y estudiantes y sitúan la universidad, en cuanto institución, en la sociedad de su tiempo y las redes de autoridad que la estructura, cuyo cumplimiento se garantiza por los propios concedentes ${ }^{2}$.

A través de él, la corporación se erigía como "constitución y organización política autónoma ${ }^{3 "}$. Pero para comprender el significado del concepto de fuero debemos

2 Alonso Romero, M. P.: Universidad y sociedad corporativa. Historia del privilegio jurisdiccional del estudio salmantino, Madrid, Tecnos, 1997, p. 34. Esta obra es fundamental para conocer la evolución del privilegio jurisdiccional o fuero académico salmantino, así como uno de los pocos estudios que existen sobre las características del fuero académico o universitario en el Antiguo Régimen. Otros trabajos para las universidades de Valladolid y Alcalá. Vid. Torremocha Hernández, M. "Una aportación al estudio de las jurisdicciones privativas. El tribunal escolástico de Valladolid durante el Antiguo Régimen” en Olmos, V. (coord.) Doctores y escolares. Congreso Internacional de Historia de las Universidades Hispánicas (Valencia, 1995). Vol. II. Valencia, Universitat de València, 1998, pp. 423-438. Torres SANZ, D.: "La jurisdicción universitaria vallisoletana en materia criminal (1589-1626)", Anuario de Historia del Derecho Español, 61(1991), pp. 5-86. Ruíz RodríGuez, I. Fuero y derecho procesal universitario complutense, Alcalá, Servicio de Publicaciones de la Universidad de la Universidad de Alcalá de Henares, 1997.

3 García Gallo, A.: “Aportación al estudio de los fueros”, Anuario de Historia del Derecho Español, 1, XXVI 
acudir a la explicación que nos ofrece la "teoría corporativa de la sociedad". De acuerdo con ella, el pensamiento social medieval estaba dominado por la idea de "cuerpo" (como organización supraindividual) autoorganizada o autorregida. Según esta concepción política, cada colectividad, entendida como una corporación o cuerpo social, por ejemplo, la universitaria, tenía una función que contribuía a un fin social colectivo, que en el caso de las universidades parece sobradamente justificado, "de modo que a cada cuerpo le debe ser conferida la autonomía necesaria para que la pueda desempeñar" ${ }^{4}$. Autonomía funcional de los cuerpos, por tanto, e idea de autogobierno, que el pensamiento medieval llamó iurisdictio, la cual garantizaba a cada uno su estatuto ("fuero", "derecho", "privilegio" o "estado") dentro de este cuerpo social. En esta concepción del poder se integraba la idea misma de justicia durante el periodo medieval ${ }^{5}$. Se trató por tanto el fuero o privilegio académico, en efecto, de una prerrogativa medievalizante que conservó el derecho de las sociedades europeas de la temprana Edad Moderna y que, si bien ciertamente modificado, también estuvo presente en la América hispana ${ }^{6}$.

En este sentido, es fundamental el marco o contexto histórico, es decir, situar la problemática de estudio dentro de su espacio geográfico y de su tiempo cronológico. En efecto, las características de la Real Universidad de México durante el siglo XVII no fueron las mismas que durante el siglo XVI, del mismo modo que la sociedad novohispana también era diferente, como muy bien trata de mostrar Leticia Pérez Puente en la introducción de su obra sobre la Universidad mexicana de la primera mitad del XVII, casi la única para este siglo ${ }^{7}$. Estamos de acuerdo con ella, en este sentido, en la existencia de cierta carencia de trabajos sobre este periodo que pongan en contacto a la sociedad con sus instituciones, así como los cambios que indudablemente se produjeron, para poder reflexionar más ampliamente sobre el ejercicio del poder y con el objetivo de encontrar explicaciones históricas que nos ayuden a comprender de forma compleja la realidad de la sociedad novohispana del siglo XVII ${ }^{8}$.

Nuestro trabajo abarca el periodo comprendido entre los años 1597, momento en el que a la Real Universidad de México se le otorga jurisdicción, y 1640 (año de la visita del obispo de la Puebla de los Ángeles Juan de Palafox y Mendoza). Se trata del periodo en que la Real Universidad de México se consolidó definitivamente como corporación, después de sus complicados años iniciales ${ }^{9}$. En este tiempo, las

(1956), pp. 387-446, p. 411.

4 Hespanha, A. M.: Visperas del Leviatán. Instituciones y poder político (Portugal, siglo XVII), Madrid, Taurus, 1989 , p. 236

5 Dice A. M. Hespanha: "Y es así que la realización de la justicia [conmutativa] -finalidad que los juristas y politólogos medievales consideran como el primero e incluso el único fin del poder político- acaba por confundirse con el mantenimiento del orden social y político establecido". HespanHA, op. cit. (nota 4) p. 236.

6 Las jurisdicciones privativas en la América hispana fueron: Consulado, Iglesia, Mesta, Minería, Protomedicato y Universidad; en tanto que las especiales eran Acordada, Bienes de difuntos, Bula de Santa Cruzada, Capellanías y obras pías, Indios, Inquisición, Real Hacienda, Recursos de fuerza, Visitas y residencias. GonzÁlez, M. del R. y LozAno, T.: "La administración de la justicia" en BoraH, W. (coord.): El gobierno provincial en la Nueva España. 1570-1787, México: UNAM-Instituto de Investigaciones Históricas, 1985, pp. 75-105, p. 82.

7 Vid. Pérez Puente, L.: Universidad de doctores. México. Siglo XVII, México, Centro de Estudios sobre la Universidad Nacional Autónoma de México, 2000. Pérez Puente, L.: Los libros de gobierno de la Real Universidad. Licenciatura en Historia, UNAM, 1992. 3v.

8 Tal y como menciona Enrique González: "el "largo" siglo XVII ha sido el gran olvidado de la historiografía virreinal y, por consiguiente, hasta hace muy poco, también de los estudiosos de la Real Universidad" en GonzÁlez GonzÁlez, E.: "Dos etapas de la historiografía sobre la Real Universidad de México (1930-2008)" en GonzÁlez González, E. y otros (eds.): Del aula a la ciudad. Estudios sobre la universidad y la sociedad en el México virreinal, UNAM-IISUE, 2009, pp. 331-410, p. 352.

9 Idea planteada por Armando Pavón y confirmada después por Leticia Pérez. Vid. PAvón Romero, A.: El gremio 
fechas que comprenden nuestro trabajo son los años de la consolidación de la corporación universitaria dentro de un marco general más amplio de lucha de poderes en Nueva España que abarcaría la segunda mitad del siglo XVI y primera mitad del XVII. Los distintos grupos de poder que competían en torno al control de la corporación universitaria durante estos años fueron: corona, virrey, audiencia, arzobispado, cabildo y órdenes religiosas, entre otros, así como un sector criollo que iba ganando importancia dentro de la sociedad novohispana, dentro de todos estos grupos, y dentro de la propia corporación universitaria, pues, tal y como señalaron Lorenzo Luna y Armando Pavón: también en el interior de la propia corporación universitaria comenzaban a consolidarse grupos con intereses específicos propios, especialmente entre el grupo de los estudiantes canonistas ${ }^{10}$.

En este sentido, hasta fechas muy recientes, buena parte de la historiografía mexicana de las universidades puso quizá demasiado el acento en la comparativa de los Estudios salmantino y mexicano, forzando en algunos puntos las comparaciones. Por ello en este artículo decidimos centrarnos en el estudio del caso mexicano atendiendo a sus características y evolución propia desde que se le fue otorgado el privilegio hasta su consolidación a lo largo de la primera mitad del siglo XVII. Nos parecen interesantes las anotaciones de la profesora Clara Ramírez al respecto cuando reflexiona sobre las limitaciones y posibilidades de estudio de las relaciones de las universidades de México y Salamanca durante la Edad Moderna: "las universidades americanas se fundaron en condiciones históricas muy particulares que marcaron y modificaron cualquier modelo propuesto"; opinión con la que coincide buena parte de la historiografía mexicana de las universidades en la actualidad: "Entonces, más que un modelo para copiar, Salamanca parece haber sido un patrón organizativo que se vio muy transformado por las condiciones concretas" ${ }^{\prime 1}$.

Esta es la opinión también del profesor Mariano Peset, quien fue uno de los primeros en comparar los fueros de ambas universidades. Sus trabajos sirvieron como punto de partida a la presente investigación. En cuanto a las fuentes documentales consultadas, el tribunal no cuenta con unos fondos propios y toda la información que sobre el ejercicio de la jurisdicción universitaria nos ha sido legada se encuentra dispersa entre los fondos del Ramo Universidad del Archivo General de la Nación (AGN) de México ${ }^{12}$. Se trata, en última instancia, este ejercicio, de una pequeña contribución a esta demanda historiográfica, así como de una invitación a futuras investigaciones sobre el tema, de la que este trabajo puede considerarse por el momento tan solo como una primera aproximación introductoria.

docto. Organización corporativa y gobierno en la Universidad de México en el siglo XVI, Valencia, Universidad de Valencia, 2010. Pérez Puente, op. cit. (nota 7, 2000), p. 105.

10 Luna Díaz, L. y Pavón Romero, A.: "El claustro de consiliarios de la real universidad de México, de 1553 al segundo rectorado de Farfán" en Universidades españolas y americanas. Época colonial, Valencia, CSICGeneralitat de Valencia, 1987, pp. 329-350, p. 346.

11 Ramírez González, C. I.: "Dos universidades del siglo XVI: Salamanca y México. Perspectivas de investigación" en González González, E. y Pérez Puente, L. (coord.): Colegios y Universidades I. Del antiguo régimen al liberalismo, UNAM-CESU, 2001, pp 39-58, p. 56 y p. 57.

12 Concretamente en los volúmenes que citamos a continuación. AGN, Ramo Universidad (RU), vol. 69. Autos fechos sobre diversas materias desde el año 1560 hasta el 1700; y AGN, RU, vol. 39. Gobierno de la Real Universidad de México, años de 1563 a 1624. En ellos aparece información variada sobre las distintas actividades que realizaba el rector, no sólo sus atribuciones jurisdiccionales, como después veremos. 


\section{Administración de la Justicia En Ciudad de México: ¿Dónde situar la jurisdicción universitaria de la Real Universidad de México?}

Dentro de la problemática general que plantea la historia del derecho indiano, cuyo estudio corresponde a la historia del derecho como ciencia jurídica, motivo por el que nosotros pasaremos a través de este apartado casi de puntillas por los grandes debates que pudiera suscitar, también porque no constituyen objeto de nuestra investigación, el hecho de que en un principio no se le reconociese jurisdicción al Estudio mexicano tiene que ver mucho con la propia concepción del poder que las autoridades coloniales plantearon respecto al territorio americano ${ }^{13}$. Es en este sentido, y con el único fin de tratar de explicar esto, por el que realizaremos un breve esquema de la administración de la justicia en Ciudad de México.

Nos ceñiremos por ello en esta ocasión tan solo al territorio ocupado por la capital de la Nueva España, es decir, la Ciudad de México, no solo para concretar el objeto de estudio, sino sobre todo para no incurrir en cualquier tipo de error que al hacer una excesiva generalización pudiésemos cometer ${ }^{14}$. Pues bien, destaca en la capital virreinal de la Nueva España el papel central que adquirió la Audiencia, tanto en las funciones de gobierno como de administración de justicia. Ésta estaba presidida por el virrey, figura también de gran importancia, que cumplía además otras funciones como la de gobernador, si bien éste, al menos en lo que a administración de justicia se refiere, generalmente respetó las decisiones de la Audiencia. Los autos de la misma, que poseían carácter obligatorio, solían ser autos acordados entre virrey y oidores, que fueron los funcionarios que conformaron la Audiencia junto con éste. El funcionamiento de la Audiencia no era similar al de las Audiencias y Chancillerías peninsulares, a pesar de inspirarse en ellas, como enseguida veremos. La Audiencia funcionó generalmente, igual que en la lejana Castilla, como tribunal de alzada, es decir, tribunal al que los súbditos de la Monarquía Hispánica podían recurrir como juzgado de segunda instancia, apelando a la mayoría de la justicia real sobre otras jurisdicciones civiles, siendo un tribunal de apelación de las sentencias falladas por los jueces menores (ya fuesen éstos alcaldes mayores o corregidores en el caso de Ciudad de México), con algunas restricciones. Del mismo modo, para los casos de corte (muerte, mujer forzada, tregua y caminos quebrantados, casa quemada, traición alevosa, pleitos de viudas, huérfanos y personas miserables o delitos cometidos por las autoridades judiciales menores), así como delitos cometidos dentro del término de cinco leguas del territorio capitalino, podía actuar como juzgado de primera instancia en tanto que juzgado de provincia. De las causas civiles se hacían cargo los ocho oidores que conformaban la Audiencia, mientras que de las causas criminales se ocupaban los cuatro alcaldes del crimen.

13 A través de una real cédula dada en Toro el 21 de septiembre de 1551 por el príncipe Felipe, futuro Felipe II, se fundaba la Real Universidad de México. El documento contenía lo siguiente: otorgaba a la nueva fundación "todos los privilegios, franquezas y libertades" que tenía y gozaba la fundación salmantina, pero con una excepción, "con tanto que en lo que toca á la juridicion se quede y este como agora está, y que la universidad del dicho estudio no execute juridicion alguna". Se conserva traslado de las tres cédulas de fundación o erección en el AGN, Ramo Universidad (RU), V. 7, fols. 2-4. Para la presente cita, seguimos la edición de las mismas de Lanning, J. T.: Reales cédulas de la Real y Pontificia Universidad de México de 1551 a 1816, México: Imprenta Universitaria, 1946, p. 293.

14 Al respecto, vid. los distintos alcances del propio concepto de "Nueva España" como "virreinato", "reino" de México, "audiencia” de México o "arzobispado" de México. Floris Margadant, G. S.: Introducción al derecho indiano y novohispano. Segunda parte: del derecho indiano al derecho novohispano, México: Lecciones de Historia 8-Fideicomiso Historia de las Américas-El Colegio de México, 2000, pp. 8-10. 
Hasta aquí todo normal, salvo que se observa una relativa jerarquización del control en que el poder organizaba la administración de la justicia, reservando un papel central para la Audiencia y sus miembros, a cuya cabeza se encontraba el virrey (y no sin la existencia de contradicciones entre ellos, por supuesto), lo que hizo que éste tribunal cobrase unas características y una fuerza de la que carecía en los territorios peninsulares, y esto se observa de forma más clara en la resolución de conflictos entre las diversas jurisdicciones, como tendremos ocasión de ver. Esto era así hasta tal punto que autores como Rafael Diego-Fernández consideran las Audiencias Indianas como unas instituciones con un grado de complejidad difícil de imaginar en la actualidad, no solo en cuanto a su función como tribunales de justicia, pues "junto a esto intervenían prácticamente en todo aquello que de importante acontecía en el Nuevo Mundo". En efecto (reproducimos la cita por su interés):

La diferencia específica entre la Audiencia y cualquier otra autoridad, radica en que era la Audiencia la que tenía en las Indias el monopolio de la ley y la justicia, y compartía el del gobierno con el virrey. Cualquier asunto relacionado con la ley en las Indias concernía directamente a las Audiencias, ya que eran ellas las que recibían, guardaban, aplicaban e interpretaban las leyes que se elaboraban en la corte para los reinos transatlánticos. Si esto ya era de por sí una enorme prerrogativa, ahora hay que agregar la de que los oidores eran los que elaboraban la mayoría de las leyes y ordenanzas vigentes en el Nuevo Mundo, y si otra corporación proponía unas ordenanzas -como los cabildos- tenían que ser aprobadas por las Audiencias" "Eso en cuanto a la vigencia misma de la ley. En cuanto a su aplicación (...) eran las Audiencias, por antonomasia, las cortes encargadas de la debida aplicación de la ley y el derecho indiano ${ }^{15}$.

Estuvieron pues, las Audiencias Indianas, en definitiva, involucradas en todas las tomas de decisión políticas y administrativas de relevancia al lado del virrey. Su papel, por tanto, era muy distinto al que desempeñaron las Reales Audiencias en la península, llegando a plantear este autor que: "el verdadero poder colonial residía en la Audiencia, y no en el cargo de virrey"16. A partir de esto, desarrolla la idea de las Audiencias como base de la organización político-territorial de América no sólo durante el periodo colonial, sino incluso después ${ }^{17}$.

Se entiende así que no fuese de recibo pues introducir demasiadas jurisdicciones especiales o privativas que pudiesen cuestionar la primacía de la Audiencia, y en los casos en los que sí que existieron y se diese conflicto entre éstas, fueron Audiencia y virrey, generalmente, los que resolvieron los conflictos jurisdiccionales que pudiesen surgir $^{18}$. En el caso de la jurisdicción universitaria, ésta tenía un carácter mucho más

15 Diego-Fernández, R.: "Una mirada comparativa sobre las Reales Audiencias Indianas” en Mazín GómEz, O. (ed.): México en el mundo hispánico. Vol. II., México, El Colegio de Michoacán, 2000, pp. 517-553, pp. 527529 .

16 Ibidem, pp. 542-543.

17 Vid. también. Diego-Fernández, R.: "De las reales audiencias Indianas" en Los caminos de la justicia en México, 1810-2012, México, Suprema Corte de la Justicia de la Nación, 2010, pp. 3-31. "Las Reales Audiencias Indianas como base de la organización político-territorial de la América Hispana” en Becerra JimÉnez, C. G. y Diego-Fernández, R. (coords.): Convergencias y Divergencias. México y Andalucia: siglos XVI-XIX, México, Universidad de Guadalajara-El Colegio de Michoacán, 2007, pp. 21-68.

18 Respecto de las justicias especial y privativa, "por lo general, en estos (...) casos, la primera instancia correspondía al tribunal que señalaban las ordenanzas del cuerpo o la materia regulada y la apelación a la Audiencia de México"; afirmación que es válida para la justicia universitaria, como después veremos. GonZÁLEZ y LoZANO. 
limitado que en los territorios peninsulares, como después veremos. Por tanto, control de la Audiencia en materia de justicia y, en última instancia, papel mediador del virrey a cuya autoridad, como presidente de la misma, se le supedita cualquier conflicto de competencia jurisdiccional. Cuando la corporación universitaria adquiriese competencias jurisdiccionales en $1597^{19}$, lo haría bajo estas prerrogativas: por un lado, con un carácter de aplicación muy limitado (y también muy reducido) respecto del papel que jugaba la Audiencia; por otro, con una fuerte presencia del virrey y de la Audiencia como elemento mediador, quienes en cierto modo venían a sustituir el papel de mediador de los conflictos que jugaba el maestrescuela en la Universidad de Salamanca, lo que limitó seriamente la autonomía del Estudio mexicano.

En efecto, en Salamanca era el maestrescuela del cabildo catedralicio quien actuaba como canciller o cancelario, juez privativo, ordinario, conservador y ejecutor de los Estatutos y constituciones de la Universidad. Y como tal, no sólo administraba justicia sino que trataba de mediar entre las conflictividades que surgían entre los distintos grupos de poder dentro del Estudio, generalmente con motivo de la elección de rector y otras predisposiciones estatutarias como las provisiones de cátedras. Sin embargo, su poder de medicación y autoridad también eran limitados (o bien el poder efectivo de los distintos grupos de poder dentro de la corporación universitaria mucho mayores), viéndose incapaz de conservar la paz en la corporación y obligado incluso en algunas ocasiones a pedir la intervención del Consejo Real de Castilla para evitar los enfrentamientos violentos entre grupos de estudiantes, organizados en naciones que competían entre sí por el control de determinados puestos de gobierno como eran las consiliaturas o el propio rectorado ${ }^{20}$. Por supuesto, en ningún caso el maestrescuela habría tenido en Salamanca la capacidad de nombrar a dedo a ningún rector como si parece que ocurría en México; tampoco el Consejo Real. Entre 1573 y 1600 todos los rectores de la Real Universidad de México fueron oidores de la Audiencia. Después de 1602 doctores universitarios, generalmente miembros del cabildo (excluyeron a los oidores hasta mediados de siglo). A partir de esta fecha, la elección del cargo de rector fue más heterogénea. Después veremos algunas injerencias del virrey que limitaban seriamente la autonomía de la corporación mexicana.

Y por terminar con este breve esquema general de la administración de la justicia en la Ciudad de México, como última instancia judicial siempre quedaba el Real y Supremo Consejo de las Indias, el cual poseía jurisdicción suprema sobre la totalidad de los territorios coloniales hispanos. En la práctica, se podía acudir a esta instancia como forma de segunda suplicación de las sentencias falladas por las Audiencias, de nuevo con ciertas restricciones, además de algunas otras funciones que no es preciso mencionar $^{21}$.

op. cit. (nota 6), p. 82.

19 Real orden de 24 de mayo de 19 de abril de 1558, que recoge la limeña, introducida por el virrey Toledo en 1580 para ésta universidad, y por la que se hace extensible el privilegio de la corporación limeña, en los mismos términos, a la mexicana. Después veremos qué términos son éstos. Para esta cita, seguimos la edición de LANNING. op cit. (nota 13), pp. 299-300.

20 Rodríguez-San Pedro Bezares, L. E.: “Cátedras, grupos de presión y naciones de estudiantes en la Salamanca del siglo XVII” en Bonilla, J. A. y Barrientos, J. (coord.): Estudios históricos salmantinos. Homenaje al P. Benigno Hernández Montes, Salamanca, Ediciones Universidad de Salamanca, 1999, pp. 485-510. Artículo también disponible en González GonzÁlez, E. y PéRez Puente, L. (coords.): Colegios y universidades I. Del Antiguo Régimen al liberalismo, México, UNAM-CESU, 2001. pp. 107-132.

21 Para ver otros vid. Muro Orejón, A. Lecciones de historia del derecho hispano-indiano, México, Escuela Libre de Derecho, 1989, pp. 27-29, 41-45, 149-164, 171-182, 215-222 y 235-242. 
Los que hemos denominado como jueces menores ${ }^{22}$, en la Ciudad de México, se dedicaban fundamentalmente a administrar justicia de carácter civil y criminal de primera instancia, tanto en la ciudad como en su distrito, y actuaron como jueces de apelación de las sentencias dadas por los alcaldes ordinarios de las villas y lugares de su jurisdicción. Del mismo modo, dentro de este esquema tal vez demasiado simplificado, pero que puede servirnos para nuestro propósito explicativo, la jurisdicción universitaria era tomada como una jurisdicción menor, pudiendo considerar al rector, en este sentido, en cuya persona recaía la administración de dicha jurisdicción, un juez menor cuyas competencias se vieron muy limitadas, como hemos podido observar y sobre las que después tendremos tiempo de reflexionar más ampliamente.

En el interés de las autoridades coloniales podríamos ver indicios de cierta centralización y jerarquización del poder, de acuerdo con una concepción moderna del poder político, tal y como destacan varios autores, además de un interés por agilizar el excesivo peso burocrático que en la península traía consigo la apertura de cualquier causa judicial, cuestión que ya venía siendo criticada por una nueva mentalidad. Se aprecia, por tanto, un proceso de "jerarquización" que Leticia Pérez pone en relación con el reflejo y refuerzo de las "líneas del ejercicio de la autoridad a imagen del centralismo monárquico"23. Estos cambios vinieron en buena medida propiciados por las sucesivas reformas de los Estatutos, las cuales se llevan a cabo tras sendas visitas en 1580 de Pedro Farfán, oidor y rector en México, el arzobispo de México Pedro Moya de Contreras en 1583, el marqués de Cerralbo en 1625 y Juan de Palafox y Mendoza, obispo de la Puebla de los Ángeles en 1640, fecha que nosotros hemos señalado como la consolidación definitiva del ejercicio de la jurisdicción universitaria en la Real Universidad de México. Intereses que formaban parte, como decimos, de esta nueva mentalidad que en los albores de la modernidad trajeron consigo los hombres y mujeres de la temprana Edad Moderna. Y a pesar de todo, los actores supieron apañárselas para buscar, en cada caso concreto, aquella instancia judicial que mejor conviniese a sus intereses. Por ello, tal vez convenga mejor echar un vistazo a la casuística con el fin de averiguar cómo la sociedad y las personas que la integraban rellenaron de contenido a las instituciones que les gobernaban, dándoles vida y legitimándolas, dotándolas, en definitiva, de contenido histórico: dejándose gobernar, hasta cierto punto, pero también amoldándolas a sus propios intereses, personales y de grupo, e incluso resistiéndose frente al dominio que en determinados momentos estas ejercieron.

\section{Características de la jurisdicción universitaria mexicana: tan cerca y tan le- jos de Salamanca}

Una vez insertada la jurisdicción universitaria de la Real Universidad de México en el lugar que ocupó dentro del esquema general de la administración de la jus-

\footnotetext{
22 Corregidores (también llamados justicias mayores), y alcaldes mayores, puesto que el virrey también ejercía el papel de gobernador de su jurisdicción (redondeando esta idea que planteamos de intento de jerarquización por parte de las autoridades coloniales). En Ciudad de México, fundamentalmente corregidores. Generalmente se apoyaban en un teniente de corregidor, letrado, que les asesoraba en materia judicial.

23 Pérez Puente, L.: "Estructura del gobierno universitario" en Marsiske, R. (coord.): La Universidad de México. Un recorrido histórico de la época colonial al presente, México, UNAM-CEU-Plaza y Valdés Editores, 2001. pp. 30-36. p. 36.
} 
ticia en la Ciudad de México del último cuarto del siglo XVI y primera mitad del XVII, se hace preciso que nos centremos en sus características más específicas. El autor que más ha tratado, y hasta el momento casi el único, la problemática de la jurisdicción de la corporación universitaria mexicana, ha sido Mariano Peset. En su interés fundamental al tratar este tema, creemos atisbar la necesidad de distinguir las Universidades de México y Salamanca como dos realidades históricas diferenciadas, especialmente en lo que concierne a la articulación de su poder y forma de gobierno, a pesar de sus ciertas interinfluencias y vínculos comunes, frente a la imagen tradicional por la que se interpretaba una Universidad novohispana, tanto en este caso en México como en Lima y otras universidades latinoamericanas, que supuestamente se habría erigido a imagen y semejanza del alma mater salmantina ${ }^{24}$. Estamos completamente de acuerdo con Mariano Peset en la necesidad de diferenciar ambas realidades ${ }^{25}$. En este sentido, definir las características de la jurisdicción universitaria mexicana es en buena medida definir muchas de las diferencias que separaban a los Estudios salmantino y mexicano, si es que queremos tomar a Salamanca como punto de origen, tal y como sí lo hacen en la época, esto también es preciso destacarlo, la mayor parte de la documentación que hace cualquier referencia al tema que tiene que ver con cuestiones universitarias como puede ser su legislación. Sin embargo, si estudiamos su funcionamiento cotidiano, enseguida podemos observar que la realidad mexicana era muy distinta de la de las universidades castellanas. Veamos esta cuestión más detenidamente.

En Castilla la normativa que daba cuerpo a la fundación de los otros dos Estudios denominados mayores, los de Valladolid y Alcalá, también hacían referencia a la fundación más antigua de Salamanca, pero configuraban de facto, del mismo modo, modelos de Universidad diferentes, lo que nos lleva a pensar en una disociación entre el discurso y la práctica en la que Salamanca tal vez apareciese más como referencia simbólica que real. Por lo que respecta a los privilegios y leyes que rigen el funcionamiento de las universidades castellanas, todas disfrutaron tanto de los mismos privilegios como de las mismas leyes, tal y como se recogen en la $\mathrm{No}$ vísima recopilación de las leyes de España ${ }^{26}$, especialmente en aquellos apartados reservados específicamente a universidades, siguiendo el modelo salmantino, como quedó recogido en dicha recopilación, por tratarse aparentemente del primero y más ilustre de todos ellos. No obstante, en las Universidades de Valladolid y de Alcalá la

24 En esta línea, vid. la obra de sor Águeda Rodríguez: RodríGuEz CRUz, A. M.: Salmantica docet: la proyección de la Universidad de Salamanca en Hispanoamérica, Salamanca, Universidad de Salamanca, 1977. De la misma autora: La universidad en la América Hispana, Madrid, Mapfre, 1992; Historia de la Universidad de Salamanca, Salamanca: Fundación Ramón de Areces-Congregación de Santo Domingo, 1990.

25 Peset, M.: Obra dispersa. La Universidad de México, México, UNAM-IISUE, 2012 p. 104, p. 132. p. 146. p. 156.

26 Editada en 1805, recoge toda la legislación precedente. Novísima recopilación de las leyes de España: dividida en XII libros: en que se reforma la recopilación publicada por el Señor Don Felipe II. en el año de 1567, reimpresa últimamente en el de 1775: y se incorporan las pragmáticas, cédulas, decretos, órdenes y resoluciones reales, y otras providencias no recopiladas, y expedidas hasta el de 1804 / mandada formar por el Señor Don Carlos IV. $2^{\mathrm{a}}$ ed. [ed. fasc. de la ed. ed. Madrid, 1805-1807]. Madrid: Boletín Oficial del Estado, 1992. esp. el libro VI en el t. III. pp. 1-278. pp. 222 y 224. Libro VIII en el t. IV pp. 1-208. p. 16 y pp. 31 y ss. (que se corresponde con el Título IV. De la Universidad de Salamanca; jurisdicción de su Juez, Rector y Maestrescuela; conservatoria y fuero escolástico de sus individuos, el cual citábamos anteriormente en la normativa salmantina) y pp. 59, 60 y 62. Libro XII en el t. V, pp. 307-530, pp. 336 y 343. En cuanto a la legislación sobre universidades en América, véase el Libro I. de la Recopilación de las leyes de los Reynos de Indias, en su título XXII, "De las Universidades y estudios particulares de las Indias" pp. 110 y ss. Disponible en http://fondosdigitales.us.es/ fondos/libros/752/14/recopilacion-de-leyes-de-los-reynos-de-las-indias [Consulta: 25 de diciembre de 2015] 
administración de la justicia quedó en manos del rector, mientras que en Salamanca, de tradición más medieval, estaba en manos del maestrescuela del cabildo catedralicio, lo que permitió el sostenimiento de cierto "equilibrio de poderes", como muy acertadamente señalaba Mariano Peset $^{27}$. El papel del rector tuvo por tanto una preponderancia desde sus orígenes, tanto en Valladolid como en Alcalá, que no tenía en Salamanca. Por tanto, podemos considerar que las Universidades de Valladolid y de Alcalá optaron por un modelo organizativo de corte moderno, más centralizado (acorde también con las tendencias de organización de la Monarquía en la época, tal y como señalábamos con anterioridad), lo que supuso también un modelo de universidad más autoritario en comparación con el salmantino. Volviendo a la "teoría corporativa de la sociedad", no era raro que las corporaciones medievales tuviesen dos cabezas, lo que permitiría un funcionamiento de carácter más "democratizante" en lo que se suponía que eran agrupaciones de iguales. En este sentido, la Universidad de Salamanca mantuvo esta "bicefalia" durante el periodo moderno, repartida entre rector y maestrescuela como cabezas del Estudio, lo que le generó multitud de conflictos entre ambas autoridades. Podemos considerar esta "bicefalia" como otro signo externo más de este carácter medievalizante. Sin embargo, para la temprana Edad Moderna, el hecho de que existiesen dos cabezas al frente de una misma corporación fue tenido como una anomalía, y por ello las nuevas fundaciones tendieron a suprimirla, optando por la concentración de poderes, lo que generó cierta jerarquización y pérdida progresiva del carácter más democrático que ciertamente presentaban muchas de estas instituciones durante el medievo. Así, las corporaciones universitarias vallisoletana o alcalaína, igual que la mexicana o la limeña, tuvieron solamente una "cabeza", el rector, evitándose al mismo tiempo algunos de los conflictos que al respecto siguieron reproduciéndose durante este periodo en Salamanca. En Salamanca el rector era un alumno elegido entre los consiliarios (miembros del claustro de consiliarios), que eran representantes elegidos a su vez entre los alumnos. En Valladolid, en cambio, era un colegial del Colegio de Santa Cruz, catedrático, elegido dentro del claustro de doctores. Del mismo modo que en Alcalá, elegido dentro del Colegio de San Ildefonso. La elección en México se hacía igual que en Salamanca, dentro del claustro de consiliarios, pero generalmente era un doctor miembro de la corporación y no un alumno.

Por lo que podemos considerar que, en cuanto al modelo organizativo de la Real Universidad de México, como decimos, se acercó más a esta otra organización de tipo más moderno (concentración de poderes en una sola "cabeza" que era además una figura de relativa autoridad y mayor prestigio, a quien se le suponía más madurez en el desempeño de su oficio). Por lo que respecta al ámbito de la jurisdicción universitaria, ésta quedó desde sus orígenes vinculada al cargo de rector, lo mismo que en Valladolid y en Alcalá, reservándose al maestrescuela, en un principio, solamente la colación de grados, junto con otras tareas menores en calidad del papel de su origen como delegado de la autoridad pontificia para el reconocimiento de grados; después veremos que esta afirmación, ampliamente aceptada por la historiografía hasta el momento, necesita ser revisada en lo que al papel del maestrescuela como autoridad dentro del Estudio mexicano se refiere. Como ya hemos visto, en un principio no se concedió jurisdicción a la corporación universitaria mexicana y fue en 1597, a imitación de su introducción en Lima por el virrey Toledo, cuando se le otorgó, aunque

27 Cuestión a la que alude de forma recurrente en la obra citada, véase PESET, op. cit. (nota 25). 
esta fue mucho más limitada que la de los Estudios mayores castellanos. Se le dotaba a las corporaciones americanas, tal y como muestra la cédula real, de jurisdicción criminal sobre todos los delitos que cometieran doctores, maestros, estudiantes y otros oficiales, salvo en los que hubiese "efusión de sangre o mutilación de miembro o pena corporal aflictiva", casos en los que conocería la justicia ordinaria de acuerdo al complejo esquema que tratamos de introducir brevemente en el apartado anterior. Analicemos más detalladamente el contenido de dicho texto:

Que el rector que es, o fuere de ella, como cabeza que de ella es, tenga jurisdicción sobre los doctores, maestros, estudiantes, y otros oficiales de la dicha Universidad (...) haya y tenga jurisdicción sobre los dichos doctores, maestros y oficiales de la dicha Universidad y sobre los lectores y estudiantes y oyentes que en ella concurren y concurrieren en todas las cosas y negocios criminales y cometieren dentro de las Escuelas de la dicha Universidad (...) como no sean delitos en que haya de haber efusión de sangre, o mutilación de miembro, o pena corporal efectiva; y en los demás delitos que se cometieren fuera de las dichas Escuelas, si fuere negocio tocante o concerniente a los dichos estudiantes, o dependiere de ellos ${ }^{28}$.

Ya fuesen, continúa, pendencias de dicho o de palabras, disputas, pagas de pupilajes u otras cosas semejantes que concerniesen a cosas de Escuelas. También podía conocer el rector en los delitos que los estudiantes tuvieran sobre juegos, deshonestidades y distracciones, pudiendo castigarles con prisión si fuese preciso; otorgándole un papel disciplinador que sería interesante estudiar en futuros trabajos. El texto terminaba destacando que: "En los demás delitos particulares que no toquen a lo que dicho es, que los dichos doctores, oficiales y estudiantes cometieren fuera de las dichas Escuelas, conozcan de ellos las demás justicias ordinarias de esta ciudad"29.

La real cedula fijaba además a las Audiencias como tribunal de apelación, como ya habíamos señalado. No comprendía jurisdicción civil como en Salamanca, Valladolid y Alcalá. Se le confería únicamente jurisdicción baja o mixto imperio con alzada a la Audiencia ${ }^{30}$. Era, en efecto, la Audiencia la instancia mediadora en los conflictos que pudiesen producirse, donde en Salamanca lo era el maestrescuela, con una relación muy estrecha con el Consejo Real, puesto que generalmente era un miembro de éste órgano. Se perfilaba, de este modo, el esquema por el cual esta institución tomaba un papel central en el gobierno colonial, también en los asuntos universitarios. Se trataba pues de una jurisdicción ratio personae y con excepciones por razón de la materia, en un espacio reducido. Es esta, en último lugar, otra cuestión que merece la pena destacarse. La jurisdicción se le confería al rector o podía ser ejercida únicamente dentro de las Escuelas (o edificio universitario ${ }^{31}$ ), excediendo

\footnotetext{
En LANNING, op. cit. (nota 13), pp. 299-302.

Ibidem.

30 A la potestad del mero imperio se le atribuye un grado de jurisdicción mayor, pudiendo aplicar penas corporales e incluso la pena capital. Al mixto imperio, por el contrario, se le atribuye una jurisdicción menor, que no incluye la aplicación de estas penas, tampoco su juicio tal y como destacábamos, en los casos en que haya efusión de sangre, etc.

31 En la península, instituciones universitarias menores como el Estudi General de València tuvieron una jurisdicción similar, aunque más limitada, que se circunscribía únicamente al edificio y cercanías de la Universidad, dejando, en última instancia, las cuestiones relevantes "a favor de la mayor autoridad del virrey y capitán general". Graullera SAnz, V.: "Revueltas universitarias en el siglo XVII" en Doctores y escolares. II. Congreso Internacional de Historia de las Universidades Hispánicas (Valencia, 1995), Vol. II., Valencia: Universitat de València, 1998, pp. 221-230. p. 230.
} 
este espacio tan solo en las faltas concernientes a disciplinamiento de los miembros de la corporación, pero no en materia criminal. Papel del rector, por tanto, como cabeza y organizador de la vida cotidiana del Estudio que debería ser destacado en futuras investigaciones. Con todo ello, podemos considerar, en definitiva, una configuración de la jurisdicción universitaria en realidad totalmente distinta a sus homólogas peninsulares, mucho más restringida y bajo una supervisión mucho más dependiente de las autoridades coloniales, como pueden ser la Audiencia o el virrey (al menos en su aplicación o ejercicio) y a pesar de las resistencias y estrategias que en muchos casos pudieron llegar a mostrar los propios miembros de la corporación, a cuya oligarquía (de las distintas autoridades coloniales, no solo la Audiencia o el virrey, ya referidas a lo largo de estas páginas) se vinculó también el control del poder dentro del Estudio.

\section{El ejercicio de la justicia universitaria y otras acciones cotidianas del rector en la Real Universidad de México: la consolidación de la corporación universi- taria mexicana}

Dicho esto pudiera parecer que ya queda poco más que añadir acerca de la jurisdicción universitaria. Sin embargo, como ya hemos referido, el siglo XVII es el siglo en el que la corporación universitaria mexicana comenzó verdaderamente a rodar como una institución consolidada, y eso podemos constatarlo a través de las fuentes de información de que disponemos para su estudio. Si en los Libros de gobierno (15631624) estudiados por Leticia Pérez veíamos la figura del rector al frente del gobierno de la corporación ${ }^{32}$, actuando de facto como auténtica "cabeza" de la misma, en los Autos fechos sobre diversas materias (1560-1700) podemos reconstruir buena parte de la conflictividad que de forma cotidiana se le presentaba a éste, o al rector reunido en el claustro de consiliarios, en el día a día al frente de la corporación. En efecto, en el transcurso de los años que nosotros decidimos establecer como marco cronológico de nuestra investigación, tenemos veintisiete expedientes en los que el rector, y no sólo él, enseguida veremos esto otro, intervino en la resolución de diversos conflictos sobre lecturas, sustituciones, cursos, matrícula, admisión de grados y hasta un auto por desacato y otro por un intento de apuñalamiento, haciendo valer, por tanto, la autoridad que de facto le confería la cédula real analizada, dando contenido, en definitiva, a la corporación universitaria en el ejercicio de su jurisdicción privativa y resto de atribuciones que desde la península se le confirieron. En otro orden de cosas, también observamos que cuando el rector pudiera verse inmerso en estos conflictos, es el caso de la elección de dicho oficio, fue en el claustro de consiliarios donde se resolvieron preferentemente estas cuestiones.

Son tres los expedientes que versan sobre problemas y enfrentamientos con motivo de la elección de rector y cátedras ${ }^{33}$. El primero de ellos, de 1593, recoge información sobre recusaciones de votos y probanzas de cursos en el que los estudiantes trataban de determinar la calidad de los votos de acuerdo con el sistema de votaciones, pues como ya sabemos, no todos los votos valían lo mismo en las votaciones

\footnotetext{
32 Véanse las conclusiones de su tesis de licenciatura: PÉrez Puente, op. cit. (nota 7, 1992), vol. 1. pp. 109-11 y 113-114.

33 AGN, RU. v. 69. Diversas Materias. Exp. 7, fols. 43-54.; Exp. 11, fols. 71-80.; y Exp. 20, fols. 151-160.
} 
de las cátedras, dependiendo del curso y la facultad en la que se encontrasen. Los otros dos, de 1611 y 1627 respectivamente, recogen información sobre conflictos en la elección de rector y consiliarios, con intervención directa de la Audiencia en el segundo caso. Veamos lo que pasó. En noviembre de dicho año los consiliarios eligieron como nuevo rector al doctor Nicolás de la Torre, lo cual enojó al doctor Alonso Vázquez de Cisneros, antiguo rector. Éste trató mal de palabra a los consiliarios que habían hecho la elección e incluso les forzó a hacer una nueva, lo que llevó a los consiliarios a recurrir lo sucedido ante la Audiencia. No lo consiguieron, a pesar de conformar la mayoría del claustro de consiliarios, y ese mismo mes presidente y oidores de la Audiencia emitieron un auto por el que declaraban que se diese posesión del oficio de rector al doctor Juan de Villabona Zubiaurre. A pesar de tratarse de una información jugosísima la que contienen estos expedientes, en el presente trabajo no nos detendremos más en su estudio, trayendo como muestra solo un botón, con el objetivo de poder centrar nuestra atención en la figura del rector como juez del Estudio y no así en otros problemas corporativos que darían lugar a un artículo separado y a extendernos demasiado. Por ello, apuntamos hacia esta veta documental como interesante línea de investigación para futuros trabajos.

Entre la documentación también hemos detectado la intervención del maestrescuela en estos conflictos cotidianos, figura para la cual se podría empezar a delimitar un papel algo más presente y con espacios de poder efectivos más interesantes que el de la simple colación de grados universitarios, también en la corporación mexicana. De este modo, el maestrescuela de la catedral, don Luis de Herrera, se dirigió el 3 de marzo de 1632 al rector a través de un auto en el que se mencionaban los Estatutos de Farfán sobre el asiento que debía de ocupar el maestrescuela en los grados de licenciados y doctores, indicando que el maestrescuela debía de preceder al rector en caso de que éste actuase como examinador. Dicho auto se notificó al rector, Cristóbal Sánchez de Guevara, el 13 de marzo, a lo que éste respondió que el maestrescuela no era su juez, y que lo que el auto contenía era fuera de estilo ni usado en la Universidad y que, por lo tanto, no parecía conveniente a su autoridad siendo como era causa de la dicha Universidad ponerle multas o hacerle notificaciones y así no tenía jurisdicción, y en caso de que alguna tuviera apelaba a la Audiencia protestando la nulidad de lo dispuesto por el maestrescuela en su auto ${ }^{34}$.

A pesar de que este conflicto pudiera parecernos un caso aislado, esta confrontación se reprodujo, con otras connotaciones, en 1634 y 1639. En el primero de los casos, estando en la sala de cabildo de la catedral en el examen de licenciado en artes de Bartolomé Amezquita, y presentes doctores y maestrescuela, don Luis de Haro, hubo algún problema con las votaciones. De acuerdo con el testimonio del maestrescuela y varios de los doctores allí presentes, el licenciado Amezquita, después de haber leído sus lecciones respondió a los argumentos y estando presto el maestrescuela a recibir los votos de los examinadores, el doctor Cristóbal Sánchez de Guevara, decano de la Facultad de artes, se levantó para ocupar la silla donde se había asistido al examinando para irse a sentar en ella y proceder con las votaciones cuando otros doctores trataron de impedírselo, formándose cierto alboroto. El problema era el turno, lo que sugiere, de nuevo, un conflicto sobre la preeminencia que debían de tener unos sobre otros, según la importancia, en dichas votaciones. El alboroto lo causó el doctor Cristóbal Hidalgo, alentado por algún otro compañero, en concreto el doctor

34 AGN, RU. Diversas Materias. Exp. 21, fols. 161-166, fol. 162 r. 
de los Ríos. Éstos pidieron votar sentados, sin moverse del sitio, mientras que el maestrescuela instó al doctor Hidalgo, que se encontraba sentado en la primera silla a la izquierda, a que la desocupase y colocase en el lugar que le correspondía para votar, pero el doctor no se quiso levantar, pidiendo que si alguien quisiese obligarlo lo hiciese por la fuerza y que se defendería si alguno de los allí presentes lo intentaba, que no querría votar de otra manera. El maestrescuela le amenazó con una multa, pero aun así, éste no se movió, a lo que don Luis de Haro terminó por pedir a los doctores que se encontraban allí presentes que votase el que quisiera, considerándolo un desacato a su autoridad ${ }^{35}$.

El segundo caso tal vez sea más representativo de estos enfrentamientos entre maestrescuela y corporación. En esta ocasión, don Luis de Haro se enfrentó al claustro pleno de la Real Universidad a través de una disputa con el síndico, Bartolomé Lucio, sobre las propinas del licenciamiento del bachiller Martín de Espinosa Monzón. En junio de 1637 el claustro pleno emitía un auto reclamándole 964 pesos de las propinas al maestrescuela. Solicitaron que se lo entregase al síndico en presencia del cancelario, como era costumbre, para que el síndico pudiese cumplir con sus obligaciones con el claustro. Como el maestrescuela hizo oídos sordos, el síndico recurrió a la Audiencia. Ésta emitió un primer auto ratificando el auto previo del claustro pleno, pero el maestrescuela recurrió y pidió que se declarase por nulo. En su defensa, hacía referencia a los Estatutos de Salamanca, mandados cumplir en México por real cédula, mientras que el síndico, por su parte, mencionaba los Estatutos de Moya. La Audiencia se pronunció en favor del maestrescuela, mandando se cumpliesen los Estatutos conforme a la costumbre castellana. El síndico recurrió, sin éxito, apelando en esta ocasión a la costumbre de la corporación mexicana. La Audiencia finalmente anuló el auto previo del claustro pleno contra el maestrescuela que, al parecer, esta vez sí logró salirse con la suya ${ }^{36}$. Estos casos, especialmente el primero y el tercero, muestran una maestrescolía, la de éste don Luis de Herrera, decidida a hacer valer su papel de conservador de los Estatutos de la Universidad ${ }^{37}$.

También se encuentra entre la documentación consultada, cuestión que no abordaremos en nuestra investigación pero que no es menos importante, especialmente si tenemos en cuenta su volumen, varios expedientes que contienen información sobre cuestiones de hacienda universitaria. En cuanto a materia de justicia, no hay pleitos civiles, los cuales abundan en Salamanca, ya que la real cédula no confería esta potestad a la corporación mexicana. Sobre dicha documentación, baste decir que es a partir de esta fecha de 1640 cuando los autos registrados comienzan a hacerse más numerosos, lo que denota un mayor interés por dejar constancia de la existencia de una corporación ya plenamente consolidada, tal y como muestran en el registro documental de sus acciones; cuestión que, además, deja las conclusiones que este trabajo pudiera presentar, como después veremos, abiertas al avance en el estudio y consulta de dichos fondos, los cuales estamos seguros que todavía aguardan valiosa información sobre éstas y otras cuestiones y en las que aquí estamos ofreciendo tan solo una pequeña muestra.

Hechas éstas aclaraciones, lo que realmente ha de interesarnos en esta primera aproximación al estudio sobre el fuero universitario mexicano, pista que nos sugirió

\footnotetext{
AGN, RU. Diversas Materias. Exp. 22, fols. 167-175

AGN, RU. Diversas Materias. Exp. 23, fols. 176-190.

37 Recordemos que en Salamanca el maestrescuela del cabildo catedralicio actuaba como cancelario, juez ordinario, ejecutor y conservador de los Estatutos y constituciones de la Universidad.
} 
la obra del profesor Rafael Diego-Fernández y con la que estamos plenamente de acuerdo $^{38}$, es la instancia en la que se resolvieron los conflictos que el ejercicio de la misma pudiese suscitar (reproducimos la cita por su interés):

En una sociedad en la que la adjudicación de ámbitos de poder pende más de principios naturales, de privilegios y concesiones, de tolerancias y costumbres, que de reglas generales incapaces de doblegar aquel dominio de pluralidad, la definición, alcance y límites de las capacidades de cada uno resultan inevitablemente determinados por los mecanismos de resolución de conflictos. Éstos se convierten en el eje sobre el cual gira el ejercicio del poder jurisdiccional. Construido el poder público sobre el concepto de Iurisdictio y teniendo la justicia una misión teóricamente definida por su función de conservación del equilibrio social, la intervención activa de la autoridad parte necesariamente del conflicto y su modo de actuación discurre por caminos esencialmente procesales ${ }^{39}$.

En este sentido, caben pocas dudas, fue la Audiencia la instancia encargada de resolver cualquier tipo de conflicto, tal y como se indica de forma clarividente en la real cédula, como decíamos anteriormente ${ }^{40}$; pero también en la práctica o aplicación de la misma. Ya hemos señalado algunos de los enfrentamientos en el claustro de consiliarios. Veamos otro de los conflictos cotidianos de la corporación. En junio de 1614 se presentaba ante el rector, don Juan de Salamanca, el catedrático de prima de leyes Juan Camas. Denunciaba irregularidades en la sustitución de su cátedra, habiéndose recibido votos sin estar presente el rector según obligaban los Estatutos. Se quejaba además de que a la votación habrían acudido oyentes que no cursaban su asignatura y pedía que se proveyese de nuevo la sustitución así como que no se admitiesen sino los votos que fuesen legítimos. El rector ordenó el traslado de la petición a la parte contraria, Gonzalo Paredes, pasante en la facultad de leyes, quien habría ganado la sustitución ${ }^{41}$. Por su parte, Gonzalo Paredes consideraba no estar obligado a responder a la petición de Juan Cano, por no haberse hecho la reclamación en tiempo y forma. Solicitó al rector la excepción de la cosa juzgada. Finalmente el rector emitió un auto por el que ordenaba que se respetasen las votaciones. Juan Cano recurrió el auto ante la Real Audiencia, "en grado de apelación, nulidad y agravio de los autos probeydos por el doctor don Juan de Salamanca, rector de la dicha Real Universidad en razón de la sustitución de la dicha mi cátedra (...)"42. La Real Audiencia, por su parte, revocó la decisión del rector y mandó que se volviese a proveer

38 Véase su "Estudio introductorio" a la obra Diego-Fernández, R. y Gayol, V. (coord.): El gobierno de la justicia. Conflictos jurisdiccionales en Nueva España (siglos XVI-XIX), Zamora (Michoacán, México), El Colegio de Michoacán-Archivo Histórico del Municipio de Colima-ALACYT, 2012, pp. 11-49.

39 AgÜEro, A.: "Capítulo I: Las categorías básicas de la cultura jurisdiccional” en Llorente SARIÑEnA, M. (coord.): De Justicia de Jueces a Justicia de Leyes: Hacia la España de 1870, Madrid, Consejo General del Poder Judicial, Centro de Documentación Judicial, Cuadernos de Derecho Judicial, VI-2006, 2007, pp. 19-58, pp. $41-42$.

40 "Y si las tales personas contra quien procediere, e a quien condenare [el rector], apelaren de las sentencias que contra ellos se dieren, les otorgará las tales apelaciones (...) para ante la Real Audiencia e Alcaldes del crimen (...)" en Lanning, op. cit. (nota 13), p. 301.

${ }^{41}$ Se incluye en el proceso la declaración de los oyentes ordinarios de prima de leyes "que para la sustituçión de la dicha cátedra se publicó la probiçión de la dicha sustituçión en un día que los más de nosotros faltamos a lecçión y se introdujeron otros que no eran votos ni oyentes y así resultó salir nombrado el dr. Gonzalo de Paredes", habiendo hecho otra elección en la persona del doctor Francisco Sánchez de Guevara. Incluye la firma de los alumnos ante el secretario de la Universidad. AGN, RU, Diversas Materias. Exp. 12, fols. 81-89, fol. 82 r.

42 Ibidem. fol. $84 \mathrm{r}$. 
la sustitución de dicha cátedra ad vota audientium y con la presencia del rector, tal y como disponían los Estatutos. La causa, por tanto, quedó en manos de la Audiencia, y el abogado de ésta solicitó a la Universidad que se confirmase el cumplimiento del auto, instándole a que lo hiciese sin dilación alguna puesto que el día de San Juan, momento en que se produjo la sustitución de la cátedra, había pasado, y desde él hasta vacaciones se habría de leer la dicha cátedra por el sustituto que saliese elegido. Entretanto, el doctor Juan Cano trató de nombrar sustituto al doctor Cristóbal Sánchez. Gonzalo Paredes reclamó que no lo podía ni debía hacer. El rector decidió entonces nombrar sustituto al doctor don Francisco de Villalobos en el ínterin en que la votación se repetía y mandó al doctor Francisco Sánchez de Guevara sub pena prestiti juramenti y de veinte reales de oro común para la obra de la Universidad se abstuviese y no prosiguiese en la sustitución de la cátedra. Francisco de Villalobos se haría cargo de las lecciones en lo que durase el pleito. La información que proporciona la documentación termina aquí. Como hemos podido observar, lo que se puso en marcha fueron distintas estrategias que iban desde la propia votación de la cátedra, hasta la decisión por parte del rector de nombrar sustituto en el último momento a otro candidato para evitar que Gonzalo Paredes se saliese con la suya. Entre medias, las disputas por el gobierno y los puestos universitarios de los diferentes grupos de poder, también a nivel interno de la corporación y no ya solo mediatizados por instancias ajenas al Estudio.

Este tipo de conflictos fueron los más habituales a los que tuvo que hacer frente el rector como "cabeza" del Estudio; conflictos en los que, como podemos comprobar la Audiencia también intervenía como instancia mediadora. También se conservan dos causas criminales en las que vemos al rector actuando como juez del Estudio. La primera de ellas se trata de un litigio por desacato hacia el rector. La segunda es un intento de apuñalamiento de un alumno hacia un maestro. En ambas el rector abrió cabeza de proceso como juez del Estudio y encargó hacer informaciones sobre los casos. Lo más importante de ambos pleitos, cuyo contenido no se conserva de manera íntegra, es el normal funcionamiento de la jurisdicción universitaria en los casos dictados por la real cedula, puesto que se trataba de causas criminales en las que no habría habido derramamiento de sangre, lo que nos muestra, de nuevo, que la corporación ejercía su jurisdicción, a pesar de todas las limitaciones, mostrando total normalidad al respecto. Lo que denota, a su vez, también cierta fortaleza corporativa, cierta autonomía, en definitiva.

En el primero de ellos el rector actuó de oficio y abrió cabeza de proceso por los sucesos ocurridos el 9 de marzo de 1617, estando reunido el claustro de rector y consiliarios. Al parecer, según las declaraciones que presentaron los testigos, el doctor Alonso Muñoz habría irrumpido en el claustro pidiendo tener unas palabras a solas con el señor rector, Antonio Roque de Coteros. Éste, por su parte, le instó a que le dijese las palabras delante del claustro, "de suerte que todos lo entendiesen que en el acto que citaba no había de oír secreto ${ }^{43 "}$, lo que hizo que Alonso Muñoz montase en cólera acusando al secretario del Estudio, Cristóbal de la Plaza, de no cumplir su oficio, y al rector de consentirlo, y que se habría de querellar con ambos, además de otras palabras entre las que se incluye, al parecer, la calificación de demonio hacia

43 A partir de este expediente, el libro que conserva estos autos pierde la referencia del número de página, con lo que las citas documentales que siguen pueden tener algún error en la foliación. AGN. RU. Diversas Materias. Exp. 16, fols. 122-125. fol. 125 r. 
el secretario del Estudio ${ }^{44}$. Fue el rector el que contestó a las acusaciones, a pesar de que Cristóbal de la Plaza se encontraba allí presente, diciéndole a Alonso de Muñoz que se cuidase de sus palabras y que su condición de clérigo y la preservación de su honor como tal no le guardaría de acusaciones tan graves contra el rector, al que estaba obligado a respetar y obedecer por su juramento.

En cuanto al segundo de los casos en materia criminal, el 4 de mayo de 1640 se presentaba ante el rector don Nicolás de la Torre, el catedrático de retórica don Juan de los Ríos, por aquel momento regente y sustituto de la cátedra de cirugía y anatomía. Denunciaba al bachiller don Antonio de Nava, cursante de medicina, de haberle intentado apuñalar. Al parecer, según las declaraciones del propio maestro y algunos estudiantes que allí se encontraron presentes, así como de varios testigos que presenciaron los sucesos, la disputa entre ambos se inició dos días antes a la salida de la lectura de la cátedra. Juan de los Ríos habría preguntado quien era el siguiente en tener las conclusiones, turno que, al parecer, recaía en el bachiller Antonio de Nava. El maestro le señaló pero éste respondió no querer tenerlas e incluso le enojó mucho el hecho de que el otro insistiera, según la declaración del propio Juan de los Ríos:

Dixo no querer tenerlas y haviéndole replicado sobre esto respondió muy irritado y al pareçer con grande cólera y enojo, tanto que me obligó a decirle el respeto y veneración con que se havian de tratar los maestros y que otros tan buenos como él havían tenido las dichas conferensias y no se dedicavan de semejantes actos, y el susodicho sin quitar el sombrero prosiguió en su irritación y enojo se fue ${ }^{45}$.

Pero la cosa no quedó ahí. Poco después de esto, el maestro acudía a casa del secretario del Estudio, Diego de Rivera, a hacerle una visita como médico cuando a la salida, bajando las escaleras y antes de subirse a su caballo, Antonio de Nava, que le estaba esperando en la puerta de la dicha casa, le intentó agredir lanzándole varias puñaladas con una daga que traía desnuda, llegándole a rasgar incluso las vestiduras, "de manera que si no retirara el cuerpo al aviso que me dio un negro mío llamado Lorenso me matara y sin duda alguna" ${ }^{46}$. Como el bachiller se iba tras de él dando grandes voces de que le habría de matar, el maestro hubo de retroceder y subir las escaleras dónde, según declaran varios testigos, fue el propio Diego de Rivera el que tuvo que acudir a meter paz, espada en mano, y calmar al bachiller. Todos los testigos que declararon coincidían en que si no hubiese sido por la intervención del secretario Diego de Rivera el suceso habría acabado mal.

$\overline{44}$ En la apertura de cabeza de proceso era el propio rector el que presentaba y describía los hechos, a pesar de ser parte de los mismos, dejando bien claro que: "para que se hagan las dilijencias que conbengan de oficio sin perjuiçio de las partes interesadas si las hubiere, mando se haga informaçión de lo suso referido y lo firmo" Ordenaba, por tanto, hacer información, siendo él mismo el que llamó a declarar a los testigos, ahora como parte. En el siguiente pleito fue también la acusación quien presentó a los testigos para la información en la cabeza de proceso. Declararon varios consiliarios. Los testimonios de todos ellos fueron vagos sobre lo sucedido, apenas dijeron que se le ofreció una silla en el claustro al lado del rector para que dijese lo que había ido a decir y que éste se descompuso, no la aceptó, y de mala forma empezó a acusar a secretario y rector, tachando al primero de diablo y diciendo que su único patrón era Su Majestad cuando el rector le llamó al orden instándole a cumplir el juramento de obediencia. Es la información del bedel, que también declaraba, la que nos ofrece más datos (tal vez por ignorancia, tal vez por solidaridad respecto al doctor Alonso de Muñoz). Éste intervino al dicho Alonso Muñoz en el tránsito de la capilla donde se celebraba el claustro y al verle tan descompuesto le acompañó a que hablase con el rector. Ibidem. fol. $123 \mathrm{r}$.

45 Ibidem. fol. $230 \mathrm{r}$.

46 Ibidem. 
Pero lo que nos interesa de este caso es el hecho de que Juan de los Ríos acudiera a pedir justicia ante el rector y señalase específicamente la real cédula por la que se confería al rector jurisdicción "porque lo susodicho tenga el remedio conveniente y el susodicho sea castigado en conformidad de la cedula de $\mathrm{Su}$ Magestad en Madrid a veinte dos de mayo de mil y quinientos y noventa y [tachado: nueve] siete (...) y mandada guardar y cumplir" ${ }^{47}$. Asimismo, amenazaba con recurrir ante el tribunal del protomedicato y cualquier otro que le conviniese con tal de que se hiciese justicia, algo que, por otro lado, era habitual en la época, como ya habíamos anotado anteriormente. Desafortunadamente, tampoco tenemos más información sobre este otro proceso más allá de la presentación de la información, con declaraciones de testigos, que hizo el doctor Juan de la Torre a petición del propio rector.

Estos casos pueden desvelarnos multitud de cuestiones sobre la vida cotidiana de los miembros de la corporación en los que podemos constatar que no siempre todos fueron tan buenos estudiantes o maestros ni utilizaron la Universidad como forma de promoción social. Volviendo a los conflictos en un sentido más amplio y dejando estos casos de materia criminal, otra cuestión a destacar es el poder de intromisión que poseía el virrey en los asuntos del Estudio, no ya solo en la elección de rectores, que como estamos viendo, podía ser considerada verdaderamente la "cabeza" y organizador de la vida cotidiana de la corporación universitaria, o a través de la presidencia de la propia Audiencia para la resolución de cualquier tipo de disputa que pudiera surgir dentro de la corporación, sino ya en cualquier elemento diario de la vida universitaria, como podía ser la colación de grados. Así, el 10 de mayo de 1640, el virrey don Lope Díez de Aux y Armendáriz, marqués de la Cadreita, expedía una dispensación, dirigida al maestrescuela, en la pompa y paseo público para recibir el grado de maestro de un religioso de la orden de San Agustín, alegada causa de necesidad por parte del religioso. El maestrescuela, de nuevo, Luis de Herrera, contestaba a los seis días y "dixo que obedecía y obedeció como auto y disposición de fuerza $(\ldots)^{\prime 48}$, sin embargo, argumentó acerca los inconvenientes que se podían seguir de no cumplirse los Estatutos y afirmaba que no era tanto el dinero que conllevaba el ceremonial:

Durando los inconbinientes que de relajar los dichos estatutos se siguen y que es mucho maior la honra y authoridad que de la dicha pompa y observancia de dichos Estatutos se sigue al graduado que la menudencia del gasto que se acrecienta y que es verosímil que quien le ayuda con lo principal por honrarle y autorisarle mas como lo merese le dará el poco gasto que para la dicha pompa es necesario ${ }^{49}$.

Efectivamente, estaba sugiriendo que fuese el propio virrey quien corriese con los gastos, permitiéndole a él que se cumpliesen los Estatutos hechos con autoridad de Su Majestad y que le correspondía hacer guardar "y me corre obligación" termina "por mi oficio de llevarlos a debida execuçión". El valor del maestrescuela frente al virrey, sin embargo, no fue suficiente y el 21 de marzo se anotaba sobre el auto del maestrescuela “(...) se cumplirá el mandamiento despachado sobre la dispensación desta pompa sin más excusa ${ }^{50}$ ". A lo que el maestrescuela respondió que lo cumpliría

\footnotetext{
$47 \quad$ AGN, RU. Diversas Materias. Exp. 26, fols. 229-234. fol. 230 r y v.

48 AGN, RU. Diversas Materias. Exp. 27, fols. 235-257. fol. 251 r.

49 Ibidem.

$50 \quad$ Ibidem. fol. $251 \mathrm{v}$.
} 
"por ser forzoso e inexcusable el obedecer" $"$. En efecto, lo más interesante de este roce es el papel del maestrescuela, de nuevo, en su faceta de "conservador" de los Estatutos y no solo el de la simple colación de grados, por muy limitado que este poder pudiera resultar frente a otras autoridades coloniales o poderes corporativos dentro del Estudio, tal y como lo demuestran éste y los otros casos expuestos.

\section{Algunas conclusiones: alcance de la autonomía de la corporación universita- ria mexicana}

Va siendo hora de cerrar este recorrido a través de las características que sobre el papel, es decir, en la legislación, y en la propia práctica y vida cotidiana del Estudio, adquirió el ejercicio del fuero o privilegio jurisdiccional de la corporación universitaria mexicana desde su concesión por la Corona en 1597 hasta el año de 1640. Para ello recogeremos algunas conclusiones y delimitaremos algunas líneas de investigación que podrían seguirse en un futuro, del que este trabajo pretende ser tan solo una introducción.

Advertíamos, al inicio de nuestro trabajo, que el fuero privativo o privilegio jurisdiccional académico es el signo externo más evidente de autonomía de las corporaciones, en este caso la universitaria, dentro de las sociedades de Antiguo Régimen, de acuerdo con la denominada teoría corporativa de la sociedad, característica del periodo medieval, pero que aún se mantiene, con algunas modificaciones, en las sociedades europeas de la temprana Edad Moderna, también en las colonias americanas. Al reconocerle un ámbito específico de jurisdicción (o iurisdictio), la corona reconocía implícitamente la consolidación de la propia corporación universitaria mexicana. En efecto, podemos considerar el ejercicio de la misma como uno de los signos más evidentes de su madurez corporativa.

Sin embargo, esta jurisdicción fue tanto más limitada de la que disfrutaron las universidades castellanas, concretamente Salamanca, pero también los otros dos denominados Estudios o universidades mayores de Valladolid y Alcalá. Ello se debe a que el desarrollo de la historia del Estudio mexicano se encuadra en un marco histórico, geográfico y cronológico, muy específico, el cual la situaba más en relación con la sociedad americana colonial que con los territorios peninsulares de la época; a pesar de que todos ellos formasen parte de los territorios de la corona castellana. Es por ello que en nuestra investigación consideramos también a la Real Universidad de México dentro de sus características y evolución propia como una manera de desvincularla de algunas comparaciones un tanto forzadas que se habrían hecho respecto al Estudio salmantino. De este modo, estaríamos de acuerdo con Mariano Peset y otros autores y autoras en la necesidad de distinguir las Universidades de México y Salamanca como dos realidades históricas diferenciadas, tanto en la articulación de su poder y forma de gobierno como en este caso, la administración de su justicia privativa.

Desde nuestro punto de vista, la jurisdicción que se otorgó por parte de la corona castellana al Estudio mexicano encaja dentro del esquema de poder trazado por la Monarquía Hispánica para las colonias americanas, el cual concedía un papel central a la Audiencia tanto en las funciones de gobierno como en la propia administración

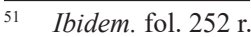


de justicia. Papel también destacado del virrey en su calidad de gobernador y presidente de la Audiencia. Se observa pues una jerarquización y centralización más marcada que en los territorios peninsulares, donde aún pesaba mucho, y más en el caso salmantino, la tradición medieval. Si bien al otro lado del Atlántico, en la lejana Castilla, estas tendencias que nosotros hemos relacionado con una concepción del poder político característica de una nueva mentalidad surgida con el desarrollo de la modernidad, que da sus primeros pasos como nueva etapa de la cultura occidental, también se dejó sentir de muy diversos modos.

Así, igual que en Valladolid o Alcalá, los otros dos Estudios mayores castellanos cuyas fundaciones compartieron esta nueva mentalidad, la jurisdicción de la corporación mexicana quedó en manos del rector. Por su parte, en Salamanca, fue el maestrescuela del cabildo catedralicio, herencia de la vinculación pontificia del Estudio medieval, quien ejerció la jurisdicción privativa. Dicha jurisdicción, en México, fue solo criminal, y no civil y criminal como en sus homólogas castellanas, incluyendo los delitos cometidos por doctores, maestros, estudiantes y otros oficiales salvo aquellos en los que hubiera efusión de sangre, mutilación o pena corporal efectiva. Se trataba, por tanto, de una jurisdicción baja o mixto imperio y no mero y mixto imperio como sí ejercía el maestrescuela del cabildo catedralicio en Salamanca, tal y como tuvimos ocasión de ampliar en el desarrollo del trabajo. Las apelaciones y resolución de conflictos jurisdiccionales deberían llevarse ante la Audiencia como tribunal de segunda instancia (justicia en alzada), pero también en función de este modelo de poder organizativo de carácter moderno, el cual dejaba para los territorios americanos la resolución de prácticamente cualquier conflicto jurisdiccional en manos de dicha institución. Era pues, una jurisdicción ratio personae y con excepciones por razón de la materia, en un espacio reducido, debido a las circunstancias expuestas.

Sin embargo, consideramos que no fue tanto este hecho como la injerencia constante del virrey en los asuntos del Estudio, lo que verdaderamente supuso un límite a la autonomía de la corporación universitaria mexicana, ya que, como hemos tenido ocasión de ver, el rector pudo ejercer su jurisdicción con aparente normalidad durante los años que nosotros estudiamos, siendo, por otro lado, las intervenciones del virrey, designando incluso los rectores que deberían ser elegidos, las que hicieron que la autonomía corporativa de la Real Universidad de México quedase innegablemente mediatizada por la acción de los poderes coloniales.

Señalamos, en este sentido, las acciones del maestrescuela don Luis de Herrera, y su empeño en aparecer ante los distintos actores y grupos que se disputaban los diferentes espacios de poder y representación política dentro del Estudio, como "conservador" de los Estatutos y constituciones de la Real Universidad de México. Sería interesante, en futuros trabajos, comparar su actividad con la de otros hombres en el desempeño del mismo oficio y ver si podríamos considerar la figura del maestrescuela en la Real Universidad de México no solo como colador de grados académicos, es decir, canciller o cancelario, sino también como conservador y ejecutor de los Estatutos y constituciones, función que sí que desempeñaba en Salamanca, junto con la de juez privativo y ordinario de la corporación universitaria.

Del mismo modo, para cerrar este trabajo de introducción, sería también interesante, en futuras investigaciones, estudiar el papel del rector en su función más amplia de "cabeza" de la corporación mexicana, juez del Estudio y disciplinador de la vida cotidiana de los miembros que dieron vida a dicha corporación, así como las 
conflictividades que surgieron de estas fricciones tanto en los claustros, con motivo de la elección de puestos de gobierno dentro de la corporación, como en la propia sociedad colonial del momento. 